\title{
A “PRINCESA” FEBRIL E O “HOSPITAL” ITALIANO, 1881-1897
}

\author{
The Feverish "Princess" and the Italian "Hospital", 1881-1897
}

\author{
Renan Vidal Mina* \\ Oswaldo Mário Serra Truzzi**
}

\begin{abstract}
Resumo. À medida que a pandemia do coronavírus impacta as condições sanitárias e socioeconômicas dos imigrantes pelo mundo afora, este artigo propõe um breve retorno ao passado brasileiro, recuperando as experiências de imigrados italianos em Campinas em fins do século XIX, igualmente atingidos por sucessivos surtos de febre amarela. Objetiva-se analisar os auxílios dos peninsulares no combate à peste através de um "hospital" adaptado na sede do Circolo Italiani Uniti (1881). Por meio de uma sistematização analítica das memórias registradas em atas pelos integrantes do sodalício e do seu cruzamento com outras fontes da época, desenvolve-se aqui um estudo de história local, em que os documentos são examinados sociologicamente, contextualizando o que está dito e os fatos.
\end{abstract}

Palavras-chave: Circolo Italiani Uniti; imigrantes; febre amarela; Campinas.

\begin{abstract}
As the coronavirus pandemic impacts on socioeconomic and sanitary conditions of immigrants around the world, this article purpose a brief return to the Brazilian past, recovering specifically the experiences of Italian immigrants settled in Campinas in the later nineteenth century, equally frightened by successive yellow fever outbreaks. The aim is to analyze the aids of the peninsulars in combating the illness through the "hospital" adapted at the headquarters of Circolo Italiani Uniti (1881). Through an analytical systematization of the memories recorded in the association's minutes by its members and their crossing with other sources of the time, is developed here a study of local history, in which the documents are sociologically examined, contextualizing what is said and the facts.
\end{abstract}

Keywords: Circolo Italiani Uniti; immigrants; yellow fever; Campinas.

Doutorando em Sociologia pela Universidade Federal de São Carlos. Campinas, SP, Brasil. E-mail: rvidalmina@gmail.com. Orcid: https://orcid.org/0000-0003-1513-4899.

** Professor Titular do Programa de Pós-Graduação em Sociologia da Universidade Federal de São Carlos. São Carlos, SP, Brasil. E-mail: truzzi@ufscar.br. Orcid: https://orcid.org/0000-0002-90465092. 


\section{Introdução ${ }^{1}$}

A propagação do novo coronavírus constitui uma das maiores preocupações no tocante à saúde pública a nível global. Assim como as mercadorias, informações, capitais e seres humanos, o referido vírus tem embarcado nas teias de mobilidade que desconsideram barreiras geográficas. Todavia, evidentemente, ele não se desloca de forma autônoma. Circula junto com os indivíduos, que são cada vez mais dinâmicos em seus movimentos (Ruseishvili, 2020). Assim, à medida que diferentes governos mundo afora adotam restrições de mobilidade, fechando fronteiras e determinando o confinamento dos sujeitos, escancaram-se as degradantes condições de vida de muitos imigrantes. Grupos étnicos oriundos do Oriente Médio, da África e da Ásia aglomerados em centros de retenção na Grécia, à deriva no Mediterrâneo, venezuelanos que se aventuram em travessias perigosas rumo à Colômbia e ao Brasil, enfim, todos expostos à contaminação pelo vírus. Aliado às dificuldades ou à total falta de acesso a condições mínimas de saúde, soma-se também, como revelado por Mantovani (2020), o aprofundamento da exploração daqueles estrangeiros já estabelecidos em um determinado país. Basta tomar como exemplo os casos dos trabalhadores bolivianos e paraguaios residentes em São Paulo, que, de maneira dramática, desvelam como a presente pandemia é marcada por raça, gênero e nacionalidade. Afinal, operando máquinas de costura, são indiretamente incumbidos de cuidar dos outros mediante a confecção de máscaras descartáveis. E isso em troca de ínfimos $\mathrm{R} \$ 0,05$ ou $\mathrm{R} \$ 0,10$ por peça.

Considerando, pois, as condições dos imigrantes em contextos de crises sanitárias, este artigo propõe um breve retorno ao passado, recuperando as experiências de uma primeira geração de italianos radicados em Campinas em fins do século XIX e que teve de lidar com sucessivas epidemias de febre amarela. Objetiva-se analisar os auxílios prestados pelos dirigentes do Circolo Italiani Uniti - a primeira mútua italiana ali fundada (17 de abril de 1881) - frente aos respectivos surtos, uma vez que, mediante enfermarias improvisadas em sua sede, o sodalício serviu de "hospital" para abrigar os patrícios infectados pelo vírus.

O enfoque deste texto não está orientado à massa de peninsulares que veio, sobretudo, para servir de mão-de-obra nos cafezais. Ele remete a indivíduos que se estabeleceram de imediato no emergente núcleo urbano campineiro. Não é demais ressaltar que, ao mesmo tempo em que a produção cafeeira conferia a Campinas o status de "capital agrícola" da província, fazendeiros e capitalistas buscavam gradativamente dotá-la de aprimoramentos em sua infraestrutura. Ferrovias para favorecer o escoamento do "ouro vermelho" e a circulação dos indivíduos, melhorias na iluminação pública, enfim, abriam-se as "porteiras" do interior para a belle époque, para a incorporação dos valores, do porte e da

\footnotetext{
1 Este artigo é fruto de uma pesquisa que conta com o apoio da Coordenação de Aperfeiçoamento
} de Pessoal de Nível Superior - Brasil (CAPES). 
indumentária de uma princesa (Ortiz, 1991). Em outras palavras, constituía-se a "Princesa do Oeste", cognome que perdurará por mais de duas décadas.

É justamente em meio ao florescimento dessa modernidade que os imigrantes italianos aqui abordados se inscrevem. Procedentes de um país recém-unificado via Risorgimento ${ }^{2}$, envolto por regionalismos e instabilidades, tais indivíduos começam a rumar ao Brasil já nos anos 1860, ou seja, antes mesmo da grande emigração. Se, ao longo desta última, estimulada, principalmente, a partir de 1888, prevaleciam famílias de camponeses subsidiadas pelo Estado brasileiro, nas primeiras levas constavam comerciantes, artesãos e profissionais liberais que se deslocavam por conta própria, individualmente ou, no máximo, acompanhados de suas respectivas companheiras.

Campinas, elevada pela economia cafeeira à condição de um dos principais polos de desenvolvimento do Brasil, figurava como um dos destinos plausíveis aos oriundi. Aproveitando o crescente trânsito de viajantes e negociantes que ali se delineava e, claro, as demandas das fazendas por produtos e serviços, os aludidos peninsulares engajaram-se na inauguração de armazéns, oficinas e fabriquetas. Gradativamente, apesar de pouco ou praticamente nada terem vivenciado da Itália enquanto Estado independente, vão deixando de se enxergar exclusivamente como vênetos, toscanos, calabreses e assumindo a identidade de italianos. Um processo que se efetiva no exterior, à medida que interagem com as populações nativas, com outros grupos de imigrados, à medida que as estatísticas do país hospedeiro assim os rotulavam, ou através de relações com representantes do governo da península. Tal percepção como um grupamento específico, diga-se, levará uma parcela dessa primeira geração de peninsulares a formar uma associação destinada a congregar seus interesses e a forjar uma identidade étnica (neste caso, a italianidade), isto é, uma imagem acerca de si, para si e para os outros (Pollak, 1992). Fomentam práticas, representações, enfim, um sentimento de pertencimento capaz de agregar pessoas de um mesmo Estado-nação mediante a suposição de uma história comum. É desse entrançado de relações que nasce o Circolo Italiani Uniti.

Ao projetarem uma sede exclusiva para abrigar uma escola voltada aos filhos dos oriundi, um salão para eventos e, acima de tudo, um hospital para atender os sócios adoecidos, os condutores da entidade deixaram registros que falam da sociedade receptora, indicando seus modos de pensar os fatos e ocorrências do dia a dia. Através das ideias, lembranças, ou ainda, da memória, inclusive a respeito da terra natal, imprimiam uma leitura particular do mundo, revelando mudanças sociais com as quais se defrontaram.

Embora tenham se inserido em uma cidade que aderia à modernidade, cumpre sopesar que esses imigrantes tiveram de lidar com um paradoxo desse

\footnotetext{
Movimento em prol da constituição da Itália enquanto Estado-nação, o qual resultou em um país integrado sob a liderança monárquica da família Savoia. Formalmente, o Estado italiano fora organizado entre 1860-1861.
} 
processo. Se, por um lado, o status de Campinas como entreposto entre o interior, São Paulo e o porto de Santos fora fundamental para o seu desenvolvimento econômico, de outro facilitara a chegada e o alastramento da febre amarela. Diante dessa conjuntura, os italianos vinculados ao Circolo projetaram-se como agentes ativos, como construtores de estratégias e práticas, auxiliando no atendimento médico à população enferma.

O que se propõe no presente artigo é uma leitura sociológica sobre um antigo episódio de crise sanitária até então tratado sob um ponto de vista essencialmente histórico. De saída, sublinha-se que a via de análise adotada está amparada na leitura e interpretação dos quatro primeiros livros de atas pertencentes à aludida instituição. Dois desses livros correspondem às assembleias gerais (o primeiro, abarcando o período de 17 de abril de 1881 a 12 de abril de 1891; e o segundo, de 4 de outubro de 1891 a 17 de julho de 1898) e os outros dois referem-se às reuniões de diretoria (o primeiro, abrangendo de 11 de junho de 1884 a 5 de julho de 1891; e o segundo, de 18 de julho de 1891 a 23 de setembro de 1898). Tais documentos foram metodologicamente sistematizados em cinco eixos centrais (história, memória, cotidiano, identidade e capital social/simbólico), de forma a fornecer um instrumental analítico capaz de proporcionar uma melhor apreensão acerca dos condicionantes que moldaram o associativismo do Circolo Italiani Uniti em um intervalo de tempo específico.

Assim, em se tratando de fragmentos produzidos pelos membros da entidade, torna-se plausível recorrer a referenciais teóricos como Pollak (1992) e Martins (2002, 2020), já que, tal qual mencionado, estamos lidando com imigrantes que documentaram algumas de suas expectativas, angústias e ações ante um período sensível não apenas para a localidade em tela, mas para si próprios. Àquela altura, à medida que buscavam estabilizar-se diante da sociedade hospedeira, a institucionalização do grupo era vista ao mesmo tempo como um meio de construção e afirmação da italianidade, e também de extensão das redes de relacionamentos para além da comunidade étnica. Vale frisar que a incorporação desses peninsulares não constituía um dado natural, ou seja, precisou ser construída através de canais e expedientes sociais. Uma vez que o sodalício estivesse instituído, manifesto, em funcionamento, aumentavam-se as probabilidades objetivas dele ser pública e oficialmente legitimado, e, por conseguinte, de seus componentes lograrem determinados benefícios. De um ponto de vista teórico, o enquadramento sociológico proposto por Bourdieu (1986, 2004a, 2004b) é bastante adequado ao fornecer um arcabouço com potencial para interpretar principalmente as estratégias de investimento social mobilizadas pelos integrantes do Circolo perante os surtos de febre amarela que marcaram a história local. Desta análise podem ser extraídos princípios observáveis em outras associações étnicas e inclusive em outras épocas. 
Paralelamente à elaboração de uma narrativa a partir das 956 páginas de transcrições (em italiano) decorrentes das atas supracitadas, buscou-se cruzá-las, ainda, com edições do Diário de Campinas e almanaques da época. Mesmo porque nem toda informação passava pela documentação oficial do sodalício. Afinal, a própria memória em si mais oculta do que revela, isto é, essas atas não são inocentes. Seus significados e condições de produção devem ser interpretados, sua leitura demanda uma contextualização do que está dito e os fatos (Martins, 2002).

Na primeira seção, apresenta-se o ambiente socioeconômico em que os primeiros imigrantes italianos se inscrevem em Campinas. A gênese da urbanização local, suas procedências e investimentos para a criação do Circolo, de modo a objetivar-se enquanto um grupo, construir uma identidade e acumular capital (social e simbólico). Na segunda parte, focaliza-se o outro lado da modernidade campineira, isto é, as temporalidades pregressas que esta ainda mantinha (Martins, 2020). Adversidades não superadas e que influíram nas epidemias de febre amarela. Destacam-se as memórias registradas pelos próprios oriundi, as quais, entrelaçadas a publicações da imprensa, ajudam a descortinar os impactos sobre os imigrantes, bem como as estratégias e os auxílios prestados pelos condutores da referida entidade.

\section{Os imigrantes italianos e a "princesa caipira"}

Conforme mencionado, os primeiros imigrantes italianos desembarcam em Campinas no momento em que o Brasil começa a se reintegrar ao âmbito das trocas internacionais. E isso graças a um produto em particular: o café. Substituindo a decadente cana-de-açúcar, cujo mercado tornava-se mais atrativo na Europa, Cuba e nas colônias antilhanas, o chamado "ouro vermelho" assumia importância comercial devido à alta de preços ocasionada pela desorganização do principal produtor de então: a colônia francesa do Haiti (Furtado, 2007). Inevitavelmente, o cotidiano campineiro, pautado àquela altura na produção açucareira, será abraçado por transformações mais amplas, objetivado por estratégias de um Estado que passa a ser gerido por um estrato que concebe as novas demandas do comércio exterior: os grandes cafeicultores. É um cotidiano, pois, que não se limita à rotina, ao íntimo (Lefebvre, 1981). Constitui algo simultaneamente concreto e abstrato, uma vez que passa a ser moldado para conferir sustentação à commodity emergente. Configura-se uma aristocracia disposta a transformar a estagnação econômica do Brasil na primeira metade do século XIX. São indivíduos abonados que se articulam e se contrapõem à centralização monárquica. Adeptos do republicanismo e de uma agenda a nível provincial, apoiavam a construção de ferrovias, o abolicionismo e o mercado de trabalho livre via imigração. Grosso modo, acreditavam que "ser moderno" implicava estar em sintonia com os modismos da Europa e dos Estados Unidos. A França, no ápice de sua 
modernidade, em que se consolidavam uma imprensa de massa e uma cultura de entretenimento, convertia-se em referência. Logo, não hesitaram em investir na cidade de Campinas, refinando-a tal qual uma princesa, a "princesa caipira".

Não é por acaso, portanto, que, à medida que os primeiros peninsulares chegavam, Campinas contava com uma quantidade razoável de estabelecimentos comerciais e fabris geridos por imigrantes portugueses e alemães. Os lusitanos avolumavam-se por ali desde 1840, enquanto os germânicos a partir de 1850 . Alguns se estabeleciam diretamente fora dos limites das fazendas, ao passo que outros, não satisfeitos com os abusos de proprietários rurais, optavam a posteriori por abandonar as colônias e a aderir igualmente à venda ou à produção de bens de consumo não duráveis.

É nesse contexto em que se delineia o mercado consumidor local e no qual expoentes da elite cafeeira investem na construção do Teatro São Carlos (1850), na fundação das companhias Paulista (1872) e Mogiana (1875), na iluminação a gás (1875), na inauguração do hipódromo (1878) e no serviço de bondes à tração animal (1879), que rostos e estaturas típicos da península começam a se inserir. Circulando pelas ruas, comprando, fabricando e comercializando produtos, encontrando escravos e ex-escravos, imigrantes lusos, alemães e os nativos, esses indivíduos vão se percebendo como um contingente distinto, como italianos.

Entre os 31.397 habitantes ali recenseados em 1872, 1.972 (6,7\%) eram estrangeiros livres. Destes, $58 \%$ dividia-se em três nacionalidades: 700 portugueses (35,5\%), 334 alemães (16,9\%) e 107 italianos (5,4\%). Números, em realidade, suficientes para impulsionar o potencial urbano local, a ponto de torná-lo mais relevante que o da própria capital paulista, que, à época, contabilizava 19.347 habitantes (Bassanezi, 1998a).

Mesmo em desvantagem em relação aos lusos e germânicos, os oriundi cresceram em medida exponencial na sequência. É bem verdade que as lacunas referentes às nacionalidades dos estrangeiros no levantamento provincial de 1886, bem como nos censos gerais de 1890 e 1900 dificultam uma leitura precisa acerca da quantidade de imigrantes italianos que se radicaram em Campinas. O que se possui de estatísticas mais aproximadas são as dos registros da Hospedaria dos Imigrantes de São Paulo. Ainda que remetam oficialmente aos indivíduos que se deslocaram em direção às lavouras de café, parece plausível imaginar que a colônia de peninsulares no limiar da década de 1880 adquiria certa expressividade, afinal, dos 2.544 estrangeiros enviados ao município entre 1882 e 1886, 1.928 (75,8\%) eram italianos (Baeninger, 1996). E mais: 61,51\% destes últimos imigraram individualmente, ou seja, desprovidos do rigoroso compromisso de prover o sustento de toda uma família, tinham mais maleabilidade e podiam arriscar o exercício de outras atividades profissionais, inclusive no núcleo urbano.

Se, em 1871, o mascate Rocco di Marco, oriundo de Salerno, e o caldeireiro e funileiro Próspero Bellinfanti, proveniente de Potenza, figuravam como uma exígua 
minoria perante o predomínio de imigrantes portugueses e alemães no tocante às atividades comerciais e fabris, a partir de 1878 evidencia-se uma inserção mais ampla e diversificada por parte dos peninsulares: conduzindo armazéns de bebidas e gêneros alimentícios, alfaiatarias, sapatarias, exercendo profissões liberais, etc. (Lisboa, 1871; Ferreira, Silva, 1878).

Conforme mencionado, é um cotidiano que vai se definindo em meio à justaposição de temporalidades pregressas e do presente. Embora concebido a partir de uma estratégia de Estado, traçada por uma elite ávida pela inovação, disposta a conferir suporte ao produto que permitia ao país readquirir relevância no comércio externo, a esta não se limitava. Isso porque o processo de urbanização igualmente avança sobre a esfera do vivido, das imediatidades, sobre o lugar das carências, dos desejos e dos comportamentos daqueles se radicavam na Campinas de fins do século XIX. E não para por aí. Entre o concebido e o vivido, existe ainda uma "zona de penumbra", que corresponde a algum nível de entendimento do mundo, funda atos, relações, valores, mensagens (Lefebvre, 1981).

Não é à toa que em 13 de fevereiro de 1880, veiculava-se na imprensa o surgimento de uma agremiação italiana de canto, possivelmente a primeira experiência associativa executada pelos peninsulares ali estabelecidos (Diário de Campinas, 1880). No ano seguinte, porém, uma iniciativa com propósitos mais amplos. A criação de uma sociedade de socorro mútuo: o Circolo Italiani Uniti. À frente desta empreitada, nomes que já acumulavam certo capital social, isto é, uma rede útil e durável de relações aptas a lhes proporcionar lucros materiais negócios, serviços - e simbólicos - reconhecimento e prestígio (Bourdieu, 1986). O aludido Rocco di Marco era um deles. Casado, desde 1875, com Theodora da Cruz, filha do fazendeiro Manoel da Cruz de Oliveira, deixara de ser um ambulante para se converter num empreendedor no varejo e no atacado. Ao seu lado, figuravam o engenheiro Samuele Malfatti e o professor de música Emilio Giorgetti, ambos de Lucca, bem como o comerciante Enrico Bolongaro, membro de uma renomada família de Verbano Cusio Ossola.

Como discutido, o associativismo italiano não constitui um fenômeno in natura. Advindos de um país recém-unificado, os oriundi desenvolvem um sentimento de pertencimento étnico ante as interações do dia a dia na sociedade de destino. A identidade nacional consiste essencialmente numa fronteira social interposta entre um grupo e "os outros" (Barth, 2011). Ela é modelada com o tempo, construindo-se e se reconstruindo nas práticas, sobretudo por intermédio de ações objetivas e subjetivas (Bourdieu, 2004a).

A começar pelo nome da entidade. A denominação Italiani Uniti não era uma escolha aleatória. Sugerida por Samuele Malfatti, constituía um "produto do senso prático como sentido do jogo, de um jogo social particular", isto é, das necessidades que demandam e exigem, que supõem por parte dos agentes invenções permanentes, indispensáveis para se adaptar às situações (Bourdieu, 
2004a, p. 81). O termo revelava o esforço em acomodar numa mesma instituição indivíduos com procedências e credos ideológicos distintos, ou seja, tanto do norte, sul e centro da Itália. A essa estratégia, vale frisar, somavam-se outras: i) os anúncios, em língua italiana, dos encontros do sodalício nas páginas da imprensa local; ii) os registros em atas, também mediante o uso da língua da mãe-pátria, das deliberações dos respectivos encontros; iii) as celebrações do Risorgimento; etc. Enfim, representações que visavam forjar uma identidade nacional, criar um consensus junto ao grupo acerca do sentido do mundo social, ou seja, consistiam, pois, em "enunciados performativos que pretendem que aconteça aquilo que enunciam" (Bourdieu, 2004b, p. 118).

Entretanto, conforme citado, não se tratava de um processo simples. Formalizar e, por conseguinte, sustentar essa identidade, essa autoimagem de uma coletividade que se percebia como italiana implicava uma complexa negociação que conciliasse as memórias de cada imigrante, de modo que suas lembranças e pontos de vista fossem assentados sobre numa base relativamente comum, ensejando uma espécie de memória coletiva (Pollak, 1992). Afinal, em se tratando de um Estado recém-constituído e atravessado por regionalismos, as memórias encontravam-se fragmentadas, em plena disputa. Logo, organizá-las através da mobilização de datas, acontecimentos, símbolos e narrativas fazia parte do repertório de estratégias de uma fração dessa primeira geração de peninsulares ali estabelecidos que, ao adquirirem certa projeção na sociedade hospedeira, manipulavam o pretérito em meio às necessidades e interesses da vida cotidiana, com vistas a um vir a ser no futuro que então se avizinhava.

Se "o mundo social é também representação e vontade" (Bourdieu, 2004b, p. 118), existir socialmente, ser percebido como um grupamento distinto, como italianos no caso, pressupõe iniciativas que aspirem à institucionalização. Desde os primeiros encontros, seja nas próprias residências dos partícipes ou em salões alugados, discutia-se a construção de uma sede particular. Para além de viabilizar atividades escolares, serviços médicos e eventos, o prédio era visto como uma forma de conferir visibilidade à associação, de amealhar capital simbólico, isto é, fazê-la conhecida e reconhecida. Sua construção inclusive denota como os fundadores do sodalício estavam inscritos em uma rede de ligações decorrente de estratégias de investimento social "consciente ou inconscientemente orientadas para a instituição ou reprodução de relações sociais diretamente utilizáveis a curto ou longo prazo" (Bourdieu, 1986, p. 22). O projeto, idealizado por Samuele Malfatti em parceria com o engenheiro-arquiteto Ramos de Azevedo, a quem auxiliou na conclusão das obras da Matriz Nova, foi apresentado aos compatriotas na assembleia de 17 de abril de 1884. Membro de uma tradicional família local, diplomado na Bélgica e já se notabilizando pela monumentalidade que conferia à cidade, Ramos de Azevedo integrava um grupo social com significativa concentração de capitais. Ele próprio era um agente com capital simbólico, dotado 
de um poder de consagrar, de dizer o que merecia ser conhecido e reconhecido (Bourdieu, 2004b).

A dupla de engenheiros planejava erigir a sede na Praça de São Benedito, também chamada à época de Largo do Riachuelo. O professor Emílio Giorgetti, àquela altura presidente da agremiação, enviou um requerimento à Câmara Municipal, solicitando a cessão de um terreno. À frente do órgão, estava o professor Amador Bueno Machado Florence, primogênito do fazendeiro Hércules Florence, fruto do primeiro matrimônio do imigrante francês com Maria Angélica Machado e Vasconcellos, falecida em 1850. Amador era irmão unilateral da professora Augusta Florence, que, ademais do status de quarta filha de Hércules com sua segunda esposa, a educadora alemã Carolina Krug Florence, era justamente casada com Emilio. Um projeto, diga-se, tributário do trabalho de sociabilidade dos oriundi, que demandava, além de uma competência específica (conhecimento das relações genealógicas e das ligações reais e arte de utilizá-las), uma disposição adquirida para obter e manter essa competência, um dispêndio constante de tempo e esforços (Bourdieu, 1986). Tanto que esse capital social por eles acumulado era reafirmado em meio à sessão da Câmara que autorizou a concessão de uma área de 3.300 metros quadrados para a referida obra. Os argumentos utilizados para chancelar a proposta do Circolo podem ser interpretados como "signos de reconhecimento" (Bourdieu, 1986, p. 22). Ao alegar que a iniciativa constituía uma "oportunidade para estreitar mais os laços de amizade com a colônia italiana", as autoridades locais estavam, em realidade, classificando e validando as "propriedades" portadas pelos membros da associação (Câmara Municipal de Campinas, 1884, p. 102-103).

Como discutido, entre o concebido e o vivido, nota-se que essa parcela de peninsulares operava um repertório de percepções. Construíam, individual e coletivamente, o mundo social, preocupam-se em formar um grupo e torná-lo legítimo, em produzir uma identidade, mobilizando representações, memórias, enfim, registrando seus modos de ver as coisas de todos os dias. A seguir, observa-se que, inseridos numa rede de relações que extrapolava a própria coletividade ali estabelecida, acumulam capital (social e simbólico) e se consolidam como agentes ativos e atuantes, sendo inclusive requisitados para auxiliar no combate às crises sanitárias que abalaram a "Princesa do Oeste", provocadas pelo vírus da febre amarela.

\section{Nem tudo é moderno: as epidemias e o Circolo}

A "pedra fundamental" da sede do círculo foi colocada em 20 de setembro de 1884. A data aludia à incorporação de Roma durante o processo de unificação italiana, fato ocorrido no mesmo dia, só que no ano de 1870. Em 2 de maio de 1886, inaugurava-se a instrução primária destinada aos filhos dos imigrantes, a qual contava inclusive com subsídios anuais do governo da península, geralmente 
intermediados pelo vice-cônsul estabelecido em Campinas. Afinal, a escola tinha um significado político: a salvaguarda da língua italiana como meio para preservar a ligação com a pátria-mãe, conservar uma identidade "preexistente".

Todavia, em relação ao hospital, havia certa distância entre desejo e realidade. Isso porque, não obstante os diálogos com os representantes consulares, as limitações de recursos para a concretização de uma obra um pouco mais complexa consistiam em empecilhos, levando os condutores da entidade a postergarem o projeto para o início do século XX. De qualquer maneira, vale ponderar que, antes mesmo de adquirir uma sede exclusiva, o Circolo oferecia serviços de saúde aos oriundi através de outra via. Observa-se que o capital social de determinados imigrantes era explorado estrategicamente para a fiação de laços com profissionais da época. Tanto que o campineiro Ataliba Florence, diplomado em Heidelberg (Alemanha), irmão de Augusta e, consequentemente, cunhado de Emilio Giorgetti, foi o primeiro médico contratado pela agremiação. Em geral, os filiados adoecidos eram consultados em clínicas particulares e as despesas enviadas à diretoria para que esta quitasse.

Os benefícios ofertados estavam circunscritos aos associados, àqueles que pagassem uma taxa de inscrição 10 mil réis em 1881 - e se mantivessem em dia com as mensalidades -1.000 réis a princípio. Ou seja, embora os condutores do sodalício mobilizassem discursos em prol da unidade da colônia radicada em Campinas, na prática, eles próprios acabavam fomentando uma clivagem social no seio da coletividade. A começar pela exigência de uma joia e de uma contribuição mensal, o que por si só era um limitador à generalidade dos conterrâneos. Sem contar que os candidatos a sócios eram submetidos a uma sindicância, com o intuito de verificar se atendiam à "idoneidade moral" requerida pelo estatuto social. Se filtrar os patrícios correspondia a uma estratégia orientada a afirmar a reputação da associação ante a sociedade hospedeira, cabe lembrar que o próprio forjamento de uma identidade étnica, como discute Bourdieu (2004a), pressupõe uma codificação que visa traçar uma linha, uma fronteira, delimitando, de acordo com a essência social que os dirigentes do Circolo atribuíam ao que significava "ser um italiano", os indivíduos que de fato podiam ser tratados como pares.

Conforme discutido, à medida que procuram incrementar seus capitais, a edificação da sede passa a ser vista por esse grupo de imigrantes como um investimento capaz de exteriorizar a pujança da associação e os seus valores, propiciando a sua visualização social. Delineado por dois profissionais sintonizados com os padrões estéticos europeus, o prédio simbolizava mais uma inovação na moderna "Princesa do Oeste". Ou, melhor, nem tão moderna assim. A despeito de seu status econômico e de alguns melhoramentos urbanos, suas condições sanitárias em fins do século XIX deixavam muito a desejar. Desprovida de rede de água e esgoto, repleta de brejos, alagadiços e com lixo acumulado em ribeirões e córregos, Campinas, àquela altura destino de boa parte dos trabalhadores 
estrangeiros que desembarcavam no porto de Santos, será atingida por uma grave epidemia de febre amarela.

Não custa lembrar que, desde a década de 1850, Santos já sofria com as moléstias. Segundo Ribeiro (1993), apesar da cidade, construída sobre terrenos de mangues e envolta por áreas pantanosas, de clima quente e úmido, naturalmente apresentar condições favoráveis à reprodução de enfermidades como a malária, a varíola, a tuberculose e a própria febre amarela, o que de fato contou para a fixação desta última foi o descaso demonstrado pelas autoridades ao longo dos anos. Com o crescimento do volume de exportações de café e do decorrente desembarque de imigrantes na cidade portuária, a situação se agravaria. De acordo com Ribeiro (1993), o surto de febre amarela iniciou-se com virulência em janeiro de 1889. De natureza então desconhecida e responsável por desencadear sintomas como febre súbita, intensa dor de cabeça e vômitos, a moléstia irrompeu com o atracamento de um vapor inglês, cuja tripulação estava acometida pelo vírus, contraído no porto do Rio de Janeiro. No fim de março, a doença já corria solta pela cidade. A epidemia só foi se extinguindo graças à chegada das temperaturas mais baixas de junho. Calcula-se que o número de mortes chegou próximo de 700 pessoas, ou seja, quase $4 \%$ do total de 18 mil habitantes que ali residiam.

Ocorre que Santos foi apenas a porta de entrada. À medida que os estrangeiros desembarcados, especialmente os italianos atraídos pela política estatal de subvenção à mão-de-obra para as lavouras de café, dirigiam-se à estação ferroviária, a doença "viajaria" pelos trilhos das companhias Paulista e Mogiana que rumavam aos núcleos interioranos. Para piorar, como mencionado, ainda não se tinha clareza de que o vírus era transmitido pelo mosquito Stegomyia fasciata ${ }^{3}$, o qual, em razão dos pântanos e da ausência de obras de saneamento, encontrara um ambiente propício em Campinas para sua proliferação.

A primeira vítima fatal no município foi uma imigrante suíça de 24 anos, chamada Rosa Beck. Não se sabe ao certo se a jovem, recém-chegada ao país, contraiu a doença ao adentrar pelo porto de Santos ou do Rio de Janeiro. De todo modo, o que vale frisar é que, sem qualquer suspeita sobre a enfermidade, ela se deslocou até Campinas a fim de empregar-se como professora de francês. Inicialmente, Rosa hospedou-se na casa de uma família de conterrâneos: os Banninger, responsáveis pela Padaria Suíça, situada na rua do Bom Jesus (atual avenida Campos Salles). Sua estadia, no entanto, seria breve. Tão logo os sintomas se manifestaram, ela não resistiu e acabou falecendo (Santos Filho, Novaes, 1996). A padaria do senhor Ulrich Banninger tornar-se-ia um foco irradiador da moléstia. Isso porque os mosquitos que picaram Rosa também picariam o proprietário do estabelecimento, familiares, funcionários e fregueses. Edwin Banninger, de 2 anos de idade, e seu pai, Ulrich, vieram a óbito nos dias 23 e 24 de fevereiro

3 Hoje denominado Aedes aegypti. A tese da transmissão da febre amarela pelo respectivo mosquito foi oficialmente confirmada em 1900, pelo médico norte-americano Walter Reed. 
respectivamente. Outro menor, o garoto Urbano, frequentador do estabelecimento, faleceria no dia 25. Nessa mesma data, era internado o padeiro suíço, João Mais, de 25 anos. João, empregado de Ulrich, foi mais um a sucumbir em 3 de março. No dia seguinte, Conrado Banninger, irmão de Ulrich, também não suportou a doença. Daí em diante, as mortes se multiplicaram. Aterrorizados, muitos habitantes de Campinas migraram para outros locais (Santos Filho, Novaes, 1996).

Nesse interim, José Paulino Nogueira, à época presidente da Câmara Municipal, amparado pelos pareceres de médicos ali radicados, ordenava a adoção de drásticas medidas de higiene preventiva. As vias públicas eram cobertas com piche, irrigadas ao anoitecer, acendiam-se e alimentavam-se fogueiras com ervas aromáticas. Tudo em nome do combate aos supostos miasmas deletérios impregnados no ar. Paralelamente, providenciava-se o transporte de doentes até os hospitais de emergência ou enfermarias improvisadas. O primeiro a recebê-los foi a Santa Casa de Misericórdia, cujas internações primitivas foram registradas a partir de 23 de fevereiro. Na sequência, à medida que a quantidade de amarelentos se expandia, instalou-se um lazareto no afastado bairro do Guanabara, em funcionamento desde 12 de março. A partir do dia 29, era a vez da Sociedade Portuguesa de Beneficência disponibilizar leitos para a coletividade lusa. Sobrou até para a Escola Correia de Melo, cujas salas também acolheram os adoecidos a partir do dia 2 de abril. E não pararia por aí.

Àquela altura, vale ressaltar, as condições sanitárias dos imigrantes italianos, já expressivamente representados nas zonas rural e urbana, geravam grande apreensão. Dentro e fora da coletividade. A ponto do presidente do Circolo Italiani Uniti, o senhor Enrico Bolongaro, veicular um informe no Diário de Campinas, alertando para o fato de que a "epidemia imperava" sobre a respectiva colônia, ameaçando não apenas os membros da entidade, mas também os patrícios mais pobres (Bolongaro, 1889, p. 3).

Até o dia 8 de março, seis integrantes do sodalício encontravam-se doentes. Os próprios termos transcritos em ata evidenciam a preocupação dos peninsulares com o avanço da febre amarela. Qualificações como "catastrófico" e "flagelo" eram utilizadas para descrever o cotidiano que vivenciavam (Circolo Italiani Uniti, 1889a, p. 293). Ou, melhor, que vivenciavam e percebiam. Afinal, após contatos com o senhor José Paulino Nogueira, decidiu-se pela suspensão parcial das atividades da entidade, de modo que a sua sede fosse exclusivamente utilizada para o atendimento de enfermos. Foram instalados 40 leitos no edifício, sendo 15 deles inaugurados no dia 4 de abril (Diário de Campinas, 1889). Destinados preferencialmente aos oriundi, mantiveram-se em funcionamento até 18 de maio, período em que a peste começou a declinar. Ali estiveram internados 133 amarelentos, dos quais 57 faleceram (Santos Filho, Novaes, 1996).

Apesar dos registros relativos ao "hospital" italiano, o cômputo geral de vítimas, em realidade, é um número desconhecido. Dados coletados pelo doutor 
Ângelo Simões, carioca, graduado pela Faculdade de Medicina da Bahia (1885) e um dos poucos médicos que permaneceu em Campinas, indicam que o total de mortos foi de 1.200 , dos quais $40 \%$ correspondiam a peninsulares. É claro que, ao menos circunstancialmente, uma epidemia de tal dimensão podia frear o crescimento demográfico do município. Se, àquele momento, sua população girava em torno de 41 a 45 mil habitantes, o censo de 1890 já captava um dos principais efeitos da febre amarela: uma redução para 33.291 habitantes (Bassanezi, 1998b).

Em fins de junho, à medida que a moléstia se abrandava, os componentes do Circolo voltavam a promover encontros a fim de planejar o retorno gradativo das atividades do sodalício. Reunindo-se nas residências de conterrâneos, discutiam, por exemplo, a necessidade da contratação de um novo médico para prestar atendimento aos sócios, uma vez que o doutor Ataliba Florence tinha saído da cidade. O nome escolhido foi o do carioca Thomas Alves Filho, um dos responsáveis pelo tratamento dos amarelentos. O acordo com o profissional, intermediado pelo comerciante de secos e molhados, Luigi Bottelli, é mais um sinal de como esse grupo de imigrantes manejava o capital social acumulado. Thomas havia se graduado pela Faculdade de Medicina do Rio de Janeiro em 1881. Radicou-se em Campinas no ano seguinte, casando-se com Maria Etelvina de Salles, filha do rico cafeicultor Manoel Reginaldo de Moraes Salles.

Outra pauta que não passou despercebida em meio a esses encontros refere-se à atuação de Enrico Bolongaro em prol dos italianos acometidos pela peste. O fato dele mesmo ter contraído e, principalmente, superado a doença enquanto auxiliava na organização das enfermarias do Circolo constituía um fator adicional para a aquisição de capital simbólico. Este último era ratificado através daquilo que se define como "alquimia da troca" (Bourdieu, 1986, p. 22). Manifestava-se o reconhecimento dos serviços prestados pelo então presidente da agremiação mediante a mobilização de signos, isto é, palavras, gestos e presentes. Enaltecido junto às atas pelo socorro às "vítimas do mal", Bolongaro foi homenageado com a fixação de um retrato numa das salas da sede social (Circolo Italiani Uniti, 1889b, p. 195-196).

Todavia, é importante ponderar que foram somente alguns meses de alívio. Em janeiro de 1890, vinha à tona um segundo surto de febre amarela. De menor vulto que o anterior, mas o suficiente para reacender o trauma da população. As internações, dessa vez, limitaram-se ao Lazareto do Fundão, que distava cerca de 2 quilômetros da área central, e às enfermarias da Sociedade Portuguesa de Beneficência, destinadas, sobretudo, aos lusitanos ali estabelecidos.

No ano subsequente, a epidemia não se repetiu. À época, autoridades municipais e sanitárias, entusiasmadas com as primeiras obras de saneamento realizadas pela "Companhia Campineira de Águas e Esgotos", empresa conduzida por Joaquim Quirino dos Santos, pelo seu filho, Bento Quirino, por Joaquim 
Floriano de Camargo e pelo advogado Gabriel Dias da Silva, todos pertencentes à elite cafeeira, apostavam que as melhorias introduzidas seriam capazes de, enfim, conter o reaparecimento da mazela. Infeliz engano! Isso porque em março de 1892 a epidemia eclodia novamente, persistindo até fins de maio. A letalidade, é verdade, não foi similar à de 1889. O assentamento de alguns canos de água e esgoto nas ruas e no interior de habitações contribuiu para atenuar o problema. No entanto, imigrantes, principalmente italianos, que continuavam a chegar de Santos, traziam o vírus consigo, uma vez que, desembarcados na cidade portuária, onde a febre amarela era uma calamidade, tornavam-se potenciais hospedeiros da doença. Sem contar, claro, que o principal causador da mesma, o mosquito, permanecia desconhecido.

Dada essa reincidência, tanto o Circolo Italiani Uniti, como o Lazareto do Fundão, a Santa Casa de Misericórdia e a Sociedade Portuguesa de Beneficência voltaram a acolher os amarelentos. Embora Santos Filho e Novaes (1996) estimem que a peste tenha vitimado 191 indivíduos, as atas da associação italiana são pouco reveladoras no tocante à instalação de enfermarias em sua sede. O que se nota, em realidade, mesmo com a suspensão das atividades cotidianas, é a disposição por parte do então presidente Giuseppe Breviglieri, dono de uma casa de câmbio e de um hotel, proveniente de Mantova, de tentar preservar o sentido do mutualismo. Na reunião de diretoria de 3 de março, anunciava aos compatriotas que, em caso da necessidade de cuidados médicos, os sócios deveriam procurá-lo para que ele providenciasse atendimento e remédios (Circolo Italiani Uniti, 1892a).

Por mais que faltem detalhes acerca dos oriundi acometidos pela doença, a ata de 30 de maio, correspondente ao primeiro encontro do Circolo após o arrefecimento da epidemia, menciona a morte de "vários sócios", possivelmente em decorrência da peste (Circolo Italiani Uniti, 1892b, p. 32). O fato é que as ondas de febre amarela impactaram as memórias daqueles que residiam em Campinas. Não é à toa que a "Princesa do Oeste", outrora pujante, passava a ser retratada como um lugar abandonado, atrelado à imagem de um cemitério (Ribeiro, 1993). Como discutido, a modernidade não se restringe ao moderno. Na América Latina, em particular, ela se constitui simultaneamente por temporalidades que não são suas, ou seja, o progresso almejado pela elite oligárquica veio acompanhado pelos vestígios de outras estruturas, por adversidades que denotavam realidades a serem superadas (Martins, 2020).

Diante disso, os trabalhos da companhia de água e esgoto seguiram. À frente deles, estava o engenheiro civil Francisco de Sales Oliveira Júnior, natural de Jacareí e mais um a integrar uma abastada família de fazendeiros. A experiência decorrente de sua graduação na Universidade de Gante (Bélgica), aliada ao background adquirido ao atuar como secretário de obras públicas da província de São Paulo foram fatores importantes para que, ao menos nos três anos ulteriores, os melhoramentos urbanos impedissem que a epidemia se manifestasse. 
Note-se: o uso da expressão "ao menos" não é aleatório. Isso porque, em fevereiro de 1896, a moléstia voltaria à luz, atingindo seu auge em abril e extinguindo-se em junho. Semelhante ciclo ocorreria no ano seguinte. Primeiro, por conta de que a aludida companhia não chegou a estender o serviço de esgoto a toda a cidade. E, segundo, devido à adaptação do ciclo evolutivo do mosquito transmissor às condições climáticas vigentes à época.

Cabe ressaltar que a sede do Circolo não foi improvisada como "hospital" em nenhuma dessas duas epidemias. Entretanto, em meio à paralisação parcial de suas atividades, o sodalício perdeu integrantes vitimados pelo vírus. As atas lavradas em 1896, em comparação com as do ano posterior, são um pouco mais detalhadas no que respeita aos efeitos da febre amarela. Na assembleia de 12 de julho, a primeira após o abrandamento do surto, o presidente Giuseppe Breviglieri comunicava que, dos 26 filiados enfermos, 7 haviam falecido (Circolo Italiani Uniti, 1896). O socorro mútuo, como de praxe, foi viabilizado mediante a mobilização do capital social acumulado pela entidade. Sua diretoria ficou a cargo de cobrir as despesas dos patrícios referentes às consultas do doutor Ângelo Simões e aos medicamentos adquiridos na farmácia do imigrante alemão Carlos Bjornberg.

A propósito, os grupos imigrados foram, mais uma vez, os principais atingidos pela peste. Trabalhadores estrangeiros, ainda não imunizados, continuavam a desembarcar na "Princesa do Oeste". De acordo com Baeninger (1996), somente para as lavouras de café, foram enviados 8.087 indivíduos entre 1887 e 1900. Destes, 6.063 (75\%) eram italianos. Não por acaso, consistiram nas maiores vítimas do vírus. Estima-se que dos 643 mortos em 1896, 253 (39,3\%) eram peninsulares, ao passo que, no ano seguinte, estes correspondiam a $171(52,6 \%)$ ante os 325 óbitos registrados (Santos Filho, Novaes, 1996).

Os surtos epidêmicos de 1896 e 1897 foram os últimos. Isso porque o governo estadual, recorrendo à doutrina higienista então em voga, resolveu interceder no saneamento local. Duas comissões ficaram responsáveis pela intervenção: a sanitária, dirigida pelo médico Emílio Marcondes Ribas, e a de saneamento, sob o comando do engenheiro civil Francisco Saturnino Rodrigues de Brito. As práticas higienistas vinham em ascensão na Europa desde o final do século XVIII (Corbin, 1987). O limpar tornava-se sinônimo não tanto de lavar, mas antes de drenar. Contando com o respaldo da elite oligárquica, aflita em desassociar o epicentro do "ouro vermelho" da imagem de reduto pestilento, as comissões imprimiram uma autêntica higienização desodorizante. O solo foi drenado, alagadiços secados, moradias desinfetadas, fossas e poços fechados. A partir dessas ações, a cidade finalmente se viu livre das epidemias de febre amarela.

\section{Considerações finais}

Em tempos em que diferentes países recorrem ao fechamento de fronteiras a fim de conter a entrada de novos imigrantes que porventura possam "transportar" 
o novo coronavírus, nota-se paralelamente a intensificação da exploração do trabalho de determinados grupos imigrados que já lograram cruzar tais limites. Exploração esta que escancara a perversidade e o cinismo da sociedade de classes contemporânea. Ora, não é demais recordar que o próprio presidente brasileiro, Jair Bolsonaro, chegou a classificar os bolivianos como "escória do mundo" (Redação, 2018). Hoje, porém, ante uma pandemia que já ceifou milhares de vidas, observam-se justamente imigrantes bolivianos e paraguaios como uns dos principais responsáveis pela confecção de máscaras descartáveis destinadas à população. Grupos, portanto, que, diante do risco de ficarem desempregados sem quaisquer benefícios, sujeitam-se à ameaça de contaminação e ao recebimento de exíguos valores em nome de cuidar dos outros, inclusive daqueles que os estigmatizam.

É nesse contexto que se optou então por recuperar a atuação de imigrantes italianos frente aos surtos epidêmicos de febre amarela que assolaram Campinas em fins do século XIX. Provenientes da periferia da Europa, ou seja, de um Estado recém-unificado, radicaram-se em um município que experimentava os ares da modernidade, que adquiria àquela altura o status de "Princesa do Oeste". Uma modernidade, porém, marcada pela coexistência de temporalidades distintas. Às ferrovias, bondes e estabelecimentos dedicados à venda de produtos importados, somava-se uma deficitária infraestrutura sanitária. A ausência dos serviços de água e esgoto formava um ambiente propício para a proliferação dos mosquitos transmissores do vírus da febre amarela. Este último, como discutido, adentrara através de imigrantes previamente desembarcados em Santos, à época epicentro da moléstia.

À medida que a maior parte dos peninsulares encontrava-se concentrada nas fazendas, submetida a precárias condições de trabalho e, consequentemente, mais exposta aos perigos da doença, uma pequena parcela dos oriundi já estabelecida no meio urbano mobilizava os capitais (social e simbólico) acumulados para viabilizar atendimento médico aos compatriotas. À frente do Circolo Italiani Uniti, esses respectivos agentes, cuja mobilidade social decorria de casamentos obtidos em meio às elites locais ou do êxito alcançado através de seus próprios negócios, intermediaram junto às autoridades a adaptação de enfermarias na sede do sodalício em dois dos cinco surtos que atingiram Campinas. E até mesmo naqueles em que o edifício não serviu como "hospital", tais imigrantes procuraram ao menos garantir auxílios aos sócios doentes mediante a cobertura de despesas médicas e farmacêuticas.

Nesse sentido, reitera-se que a retomada de crises sanitárias pregressas e, claro, um exame sobre os impactos e os auxílios prestados pelos imigrantes para lidar com seus efeitos, são absolutamente propícios nessa atual conjuntura. Não se trata aqui de fazer um prognóstico acerca do futuro da mobilidade humana pós-pandemia. Pelo contrário. Como discute Ruseishvili (2020), restam dúvidas 
se prevalecerá uma temerária banalização das medidas restritivas referentes à liberdade de movimento, ou se as dolorosas "cicatrizes" deixadas pela covid-19 ajudarão a convencer as sociedades que apenas ações coletivas, solidárias e universais são capazes de proteger as populações de epidemias, da pobreza e da violência. A questão central suscitada neste artigo, mediante o recurso a uma perspectiva histórico-sociológica, é chamar a atenção para a importância da promoção de uma agenda social que de fato contemple as populações imigrantes, tão fundamentais para a nossa sobrevivência.

\section{Referências bibliográficas}

BAENINGER, Rosana. Espaço e tempo em Campinas: migrantes e expansão do polo industrial paulista. Campinas: Editora da Unicamp, 1996.

BARTH, Fredrik. Grupos étnicos e suas fronteiras. In: POUTIGNAT, Philippe; STREIFFENART, Jocelyne (orgs.). Teorias da etnicidade. 2 ed. São Paulo: Editora Unesp, 2011, p. 185-227.

BASSANEZI, Maria Silvia Casagrande Beozzo. São Paulo do passado: dados demográficos, 1872. Campinas: NEPO, 1998a.

BASSANEZI, Maria Silvia Casagrande Beozzo. São Paulo do passado: dados demográficos, 1890. Campinas: NEPO, 1998b.

BOLONGARO, Enrico. Circolo Italiani Uniti (1889). Diário de Campinas. Campinas, 04.04.1889.

BOURDIEU, Pierre. The forms of capital. In: RICHARDSON, John G. (org.). Handbook of theory and research for the Sociology of Education. Westport: Greenwood, 1986, p. 16-29.

BOURDIEU, Pierre. Coisas ditas. Tradução de Cássia R. da Silveira e Denise Pegorim. São Paulo: Brasiliense, 2004a.

BOURDIEU, Pierre. O poder simbólico. Tradução de Fernando Tomaz. 7. ed. Rio de Janeiro: Bertrand Brasil, 2004b.

CÂMARA MUNICIPAL DE CAMPINAS. Livro de Atas das Sessões, 9 abr. 1883 a 10 jan. 1885. Campinas, 10.05.1884.

CIRCOLO ITALIANI UNITI. Livro de Atas das Reuniões de Diretoria, 11 jun. 1884 a 7 jul. 1891. Campinas, 09.03.1889a.

CIRCOLO ITALIANI UNITI. Livro de Atas das Assembleias Gerais, 17 abr. 1881 a 12 abr. 1891. Campinas, 01.09.1889b.

CIRCOLO ITALIANI UNITI. Livro de Atas das Reuniões de Diretoria, 18 jul. 1891 a 23 set. 1898. Campinas, 03.03.1892a.

CIRCOLO ITALIANI UNITI. Livro de Atas das Reuniões de Diretoria, 18 jul. 1891 a 23 set. 1898. Campinas, 30.05.1892b.

CIRCOLO ITALIANI UNITI. Livro de Atas das Assembleias Gerais, 04 out. 1891 a 17 jul. 1898. Campinas, 12.07.1896.

CORBIN, Alain. Saberes e odores: o olfato e o imaginário social nos séculos XVIII e XIX. São Paulo: Companhia das Letras, 1987. 
FERREIRA, Carlos; SILVA, Hypolito da. Almanach popular de Campinas para o anno de 1879. Campinas: Typographia da Gazeta de Campinas, 1878.

FURTADO, Celso. Formação econômica do Brasil. 34 ed. São Paulo: Companhia das Letras, 2007.

LEFEBVRE, Henri. Critique de la vie quotidienne. Paris: L'Arche, 1981.

LISBOA, José Maria. Almanak de Campinas para 1872. Campinas: Typographia da Gazeta de Campinas, 1871.

MANTOVANI, Flávia. Imigrantes em SP ganham R \$0,05 para confeccionar máscaras anticovid. Folha de São Paulo, São Paulo, 18.07.2020. Disponível em: < https:// www1.folha.uol.com.br/mundo/2020/07/imigrantes-em-sp-ganham-r-005-paraconfeccionar-mascaras-anticovid.shtml>. Acesso em: 20.07.2020.

MARTINS, José de Souza. Subúrbio. Vida cotidiana e história no subúrbio da cidade de São Paulo: São Caetano, do fim do Império ao fim da República Velha. 2. ed. São Paulo: Hucitec, 2002.

MARTINS, José de Souza. A sociabilidade do homem simples: cotidiano e história da modernidade anômala. São Paulo: Contexto, 2020.

NOVA ENFERMARIA. Diário de Campinas. Campinas, 05.04.1889.

ORTIZ, Renato. Cultura e modernidade: a França no século XIX. São Paulo: Editora Brasiliense, 1991.

POLLAK, Michael. Memória e identidade social. Estudos Históricos, v. 5, n. 10, p. 200215, 1992.

REDAÇÃO. Bem antes de Trump, Bolsonaro chamou haitianos e outros imigrantes de "escória do mundo". Gazeta do Povo. Curitiba, 16.012018. Disponível em: < https://www.gazetadopovo.com.br/politica/republica/eleicoes-2018/bem-antesde-trump-bolsonaro-chamou-haitianos-e-outros-imigrantes-de-escoria-do-mundobvhv8jc0gsf15ueai7od4uy0l/>. Acesso em: 15.07.2020.

RIBEIRO, Maria Alice Rosa. História sem fim: inventário da saúde pública, São Paulo (1880-1930). São Paulo: Editora da Unesp, 1993.

RUSEISHVILI, Svetlana. Quatro lições da pandemia sobre a mobilidade no mundo contemporâneo. Disponível em: <http://www.ppgs.ufscar.br/sociologia-napandemia-5/>. Acesso em: 16.05.2020.

SANTOS FILHO, Lycurgo de Castro; NOVAES, José Nogueira. A febre amarela em Campinas, 1889-1900. Campinas: Centro de Memória da Unicamp, 1996.

SOCIEDADE ITALIANA DE CANTO. Diário de Campinas. Campinas, 13.02.1980. 